\title{
EFFECTS OF INTERFACIAL GEOMETRY ON LASER JOINING OF DISSIMILAR NITI TO STAINLESS STEEL WIRES
}

\author{
Grant B. Brandal, Gen Satoh, Y. Lawrence Yao \\ Columbia University \\ Department of Mechanical Engineering \\ New York, NY, USA \\ Syed Naveed \\ Boston Scientific Corp. \\ Marlborough, MA, USA
}

\begin{abstract}
Joining of the dissimilar metal pair NiTi to stainless steel is of great interest for implantable biomedical applications. Formation of brittle intermetallic phases requires that the joining processes limit the amount of over-melting and mixing along the interface. Thus, laser joining is a preferred method due to its ability to precisely control heat input. This study explores a method of using a cup and cone interfacial geometry, with no filler material, to increase the tensile strength of the joint. Not only does the cup and cone geometry increase the surface area of the interface, but it also introduces a shear component, which is shown to be beneficial to tensile strength of the wire as well. The fracture strength for various cone apex angles and laser powers is determined. Compositional profiles of the interfaces are analyzed. A numerical model is used for explanation of the processing.
\end{abstract}

\section{INTRODUCTION}

In order to exploit specific material properties in different places of products, it is often beneficial to join dissimilar materials. Joining dissimilar materials can help to optimize toughness, wear resistance, chemical resistance, thermal properties, hardness, flexibility, etc. Many different types of dissimilar materials can be joined (ceramics, composites, polymers), but this paper will focus on the joining of dissimilar metals.

Due to some of its unique properties, nickel titanium (NiTi) is receiving increasing use, especially in implantable medical devices. NiTi has good biocompatibility, which makes it ideal for implantable medical devices. Once inside the body, NiTi's radiopacity makes it easy to be located by imaging devices. Especially due to its shape memory effect and superelasticity, NiTi can allow for less invasive procedures.
Some examples of current NiTi applications are stents, Simon vena cava vein filters, and atrial Septal defect occlusion systems [1]. Obviously, implantable medical devices are not made simply out of a single material, which is why techniques for joining NiTi to other materials must be explored. A common pair is joining nickel titanium to stainless steel (SS), using stainless steel where NiTi is unnecessary. Using stainless steel in places where shape memory and superelasticity are not required can help to reduce the part cost.

The process chosen for joining a dissimilar material pair is heavily dependent on the composition of the materials of interest, and also on the specifications for the finished product [2]. Possibly the simplest way to join dissimilar materials is by using adhesives. Adhesives are sensitive to temperature, and their strength heavily relies on the amount of moisture that is absorbed $[3,4]$. Clearly this is not viable for implantable medical devices. Since many dissimilar metal pairs have a tendency to form intermetallics when heat is used for joining [5], several different methods to minimize the amount of intermetallic formation have been reported. One proposed method is by using friction stir welding. This process reaches lower temperatures, and thus may help minimize intermetallic formation [6]. Friction stir welding of magnesium and aluminum has been shown to be possible, but it was found that the hardness across the joint became twice that of the base materials [7]. Fracture occurred at the point with the highest hardness gradient. Significantly changing the material properties is undesirable, and it was also found that there was a very narrow range for working parameters (rotation speed, weld speed). Also, friction stir welding is not easily applied to the wire geometry currently of interest. Another method is to melt a filler material that is placed between the two materials, and never directly melt the base materials. When choosing a filler 
material, it is important that its thermal expansion properties are similar to the materials being joined, otherwise large residual stresses will form. Nickel-chromium filler materials are often used when joining stainless steels, since they have comparable thermal properties [2]. Using zinc as a filler, Mathieu was able to achieve tensile strengths of 240MPa when joining aluminum to stainless steel [8]. But, it is also possible to take advantage of the large difference of melting temperature between these materials. Stainless steel has a much higher melting temperature than aluminum. By laser irradiating the stainless steel side, the heat will conduct across the interface and melt the aluminum [5]. This eliminates the need for a filler material, but is restricted to material pairs with large melting temperature differences.

The dissimilar metal pair of NiTi and stainless steel, which is of interest to the medical world, does not have a very large melting temperature difference. A process for joining nickel titanium and stainless steel wires together, without using a filler material, was proposed by Satoh et al. [9]. Their process, however, is limited in that it is difficult to apply uniform heating at the interface for larger diameter wires. This paper will introduce a method that can be applied to thicker wires. In joining processes, the interface geometry can be altered to maximize the effectiveness of the process being used. For example, including an extra lip of material along the top of a seam to be electron beam welded can provide material to fill any gaps that form [10]. To evenly heat the thicker wires currently of interest, they will be rotated during laser irradiation. A cup and cone interfacial geometry is proposed. This will help to keep the wires aligned during rotation, and also increase the surface area of the interface, resulting in higher strength. The tip of the stainless steel wire is shaped into a point, and the nickel titanium is shaped as an inverted cone, whereby the stainless steel can fit into it. This results in a net increase of surface area of the interface, without increasing the outside diameter of the joint. Different angles of cones were analyzed. To allow for even heat distribution, the wires were rotated while being irradiated. The effect that different laser power levels had on each of these angles is presented.

\section{BACKGROUND}

\section{Ternary Phase Diagram and Brittle Intermetallics}

Two of the most useful properties of nickel titanium are its superelasticity and shape memory effect. The superelasticity is due to a diffusionless martensitic transformation that occurs under large strains. This transformation is from austenitic BCC B2 into an HCP B19 crystal structure. The Clausius-Clapeyron relation indicates how, under an induced stress, martensite can form at temperatures higher than the martensite start temperature $M_{s}$ [11]. When nickel titanium has been deformed in its martensitic phase, heating to the austenitic phase will cause it to recover its original shape; this is the shape memory effect.

One of the biggest concerns when joining dissimilar metals is the formation of brittle intermetallic phases.

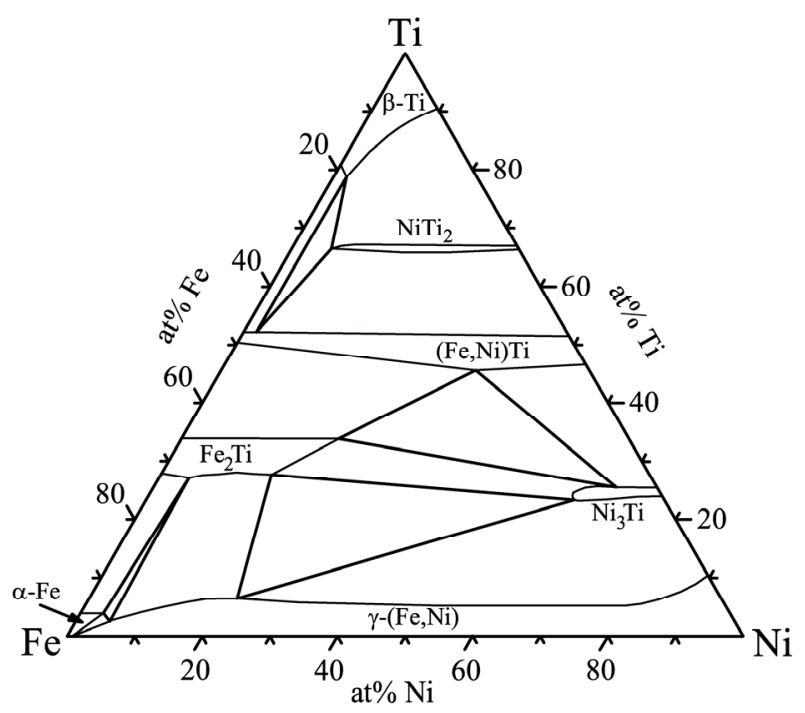

Figure 1 Ternary phase diagram for Fe-Ni-Ti at 1173K [12].

Intermetallics form in very specific proportions, and have crystal structures that differ from the original base materials. Electrical, mechanical, magnetic, and chemical properties may be different from the base materials as well [13]. The specific ratios they form in makes it possible to identify phases present in a sample by using EDX analysis. Many intermetallics are subject to brittle fracture and suffer from a low crack tolerance. Their complex crystal structures have large Burgers' vectors, so it often requires less energy for fracture than for dislocation movement. A ternary phase diagram for titanium, iron, and nickel is shown in Figure 1. This is at $1173 \mathrm{~K}$, about $400 \mathrm{~K}$ below melting temperature for the NiTi. For simplification, we can neglect the effects of the chromium that is present in the stainless steel. Chromium would behave similarly to the titanium, and there is much less of it than the other three materials [14]. $\mathrm{Fe}_{2} \mathrm{Ti}$ is a Laves phase, and has some unique magnetic properties [15]. But, due to its C14 hexagonal structure is quite brittle [16]. The other common intermetallic formed is FeTi. Large regions of FeTi have been shown to decrease the tensile strength of the joint [17]. Nickel titanium and stainless steel have different thermal expansion coefficients, and van der Eijk et al. concluded that this difference could result in stresses and initial cracks within the intermetallic layer [18]. Using a nickel interface layer may help to lessen the amount of brittle intermetallics formed, but it will not completely prevent their formation [18]. Shortening the time period that the base materials are at or above melting temperature will limit intermetallic formation also. Borrisutthekul et al. found that placing a heat sink with a large thermal conductivity next to the joint lowered the amount of intermetallics formed when joining steel to aluminum [19]. If over-melting occurs at the interface, iron from the stainless steel can substitute for nickel in the NiTi's austenitic phase, lowering the martensitic start temperature $\mathrm{M}_{\mathrm{s}}$ and allowing for the formation of an $R$ phase [20]. This lowered $M_{s}$ and 
decrease of nickel concentration will also result in the superelastic plateau occurring at a lower stress [21].

Phase change is not limited to the interface. Due to the laser heating, a heat affected zone in the base materials will also undergo some changes. Precipitates in the base NiTi will increase, which also results in lowering the $\mathrm{M}_{\mathrm{s}}$ temperature [22]. Once the NiTi has recrystallized, the thermodynamic parameters will remain nearly constant though [23].

\section{Geometrical Considerations}

Characterization of the quality of each joint is based on its tensile testing results. Since the dissimilar material pair has different Young's Moduli, the stress-strain response does not have a clear, direct interpretation. Thus, the most important characteristic is the load at fracture for each joint. The fracture strength of joints can be increased by distributing the load over a larger surface area. Different interface geometries can be used to increase the contact area, without increasing the overall size of the part. Increasing the surface area will decrease the stress concentration on the interface, but sharper angles may have detrimental effects on surface wetting [24]. This places a limitation on the geometries in that they must not be too complex. One possibility is to make a U slot, and slide one piece around the other. Vaidya et al. used this method for butt welding plates of aluminum AA6605 and titanium Ti6A14V [25]. Fracture occurred in a heat affected zone, and not at the interface itself. The simplest way to increase the interface surface area for wires is to cut the ends at an angle. This will result in an increase of surface area, given by $A=\frac{A_{o}}{\cos (\varphi)}$, where $A_{o}$ is the cross sectional area of the wires, and $\varphi$ is the angle between the normal of the surface and the longitudinal axis of the wire. This is a viable option to be applied to the $381 \mu \mathrm{m}$ diameter wires that Satoh explored [9]. But, the wires of current interest have twice that diameter. Getting the heat to conduct through thicker wires and evenly melt the interface is not viable. Overheating must be avoided, as simply melting the base $\mathrm{NiTi}$, without any mixing or intermetallic formation occurring, can decrease the tensile strength of the wire by as much as 30\% [26]. One solution is to use multiple lasers, and simultaneously irradiate the top and bottom of the sample [25]. But due to the rotational symmetry of the wires, an alternative method is to use a single laser source but rotate both of the wires during the laser scan. This paper will make use of this wire rotation.

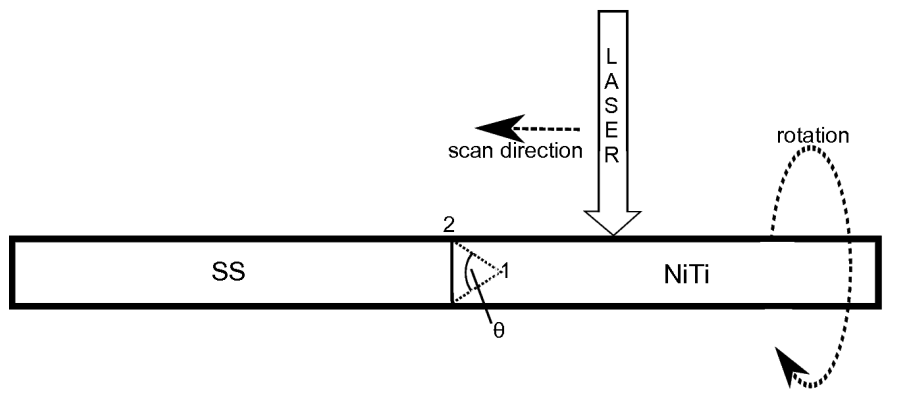

Figure 2 Schematic diagram describing the geometry used. Point 1 is at the apex of the cone, point 2 is on the outside edge.

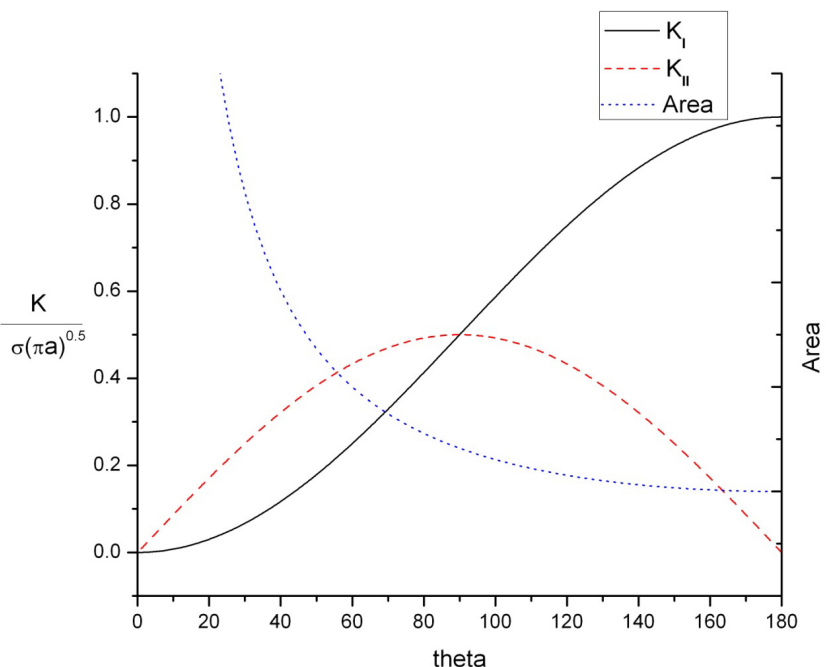

Figure 3 Mode I stress intensity $\left(\mathrm{K}_{\mathrm{I}}\right)$ and Mode II stress intensity $\left(\mathrm{K}_{\mathrm{II}}\right)$ versus angle of interface, for a constant uniaxial load. The interfacial area is superimposed over-top, indicating that as the cones become sharper, the area increase results in a decrease of stress intensity.

To increase the interfacial surface area, a cup and cone geometry is proposed, as shown in Figure 2. The stainless steel will be shaped into a point, while the end of the NiTi is drilled out in the shape of a cone. An angle $\theta$ is defined as the apex angle of the cone. Two different apex angles will be analyzed $\left(90^{\circ}\right.$ and $\left.120^{\circ}\right)$ and their strengths compared to wires without the conical interfaces. The $90^{\circ}$ cones will have an interface area of $0.645 \mathrm{~mm}^{2}$ while the $120^{\circ}$ cones will be $0.527 \mathrm{~mm}^{2}$, which are $41 \%$ and $16 \%$ larger than a flat interface, respectively. Of course, this increased surface area is not normal to the direction of loading, and as such we do not expect the fracture load to increase the same amount as the surface area.

\section{Stress Intensity Formulation}

Stress intensity in uniaxial tension along a crack oriented at an angle is given by

$$
\begin{gathered}
K_{I}=\sigma \sqrt{\pi a} * \sin ^{2} \frac{\theta}{2} \\
K_{I I}=\sigma \sqrt{\pi a} * \sin \frac{\theta}{2} \cos \frac{\theta}{2}
\end{gathered}
$$

where $\sigma$ is the applied stress, a is crack length, $\frac{\theta}{2}$ is the angle between the applied load and the crack [27]. We assume that the cracks formed will be in areas that did not melt along the interface, and also that the fracture will propagate along the joint interface, within the intermetallic layer. Therefore, the cracks will be oriented $\frac{\theta}{2}$ degrees from the direction of loading as well. Figure 3 shows these $\mathrm{K}$ values for various interfacial angles. For an ideally brittle material, $\frac{K_{I I C}}{K_{I C}}=1.2$ [28], where $\mathrm{K}_{\mathrm{IIC}}$ is mode II fracture toughness and $\mathrm{K}_{\mathrm{IC}}$ is mode I fracture toughness. From the graph we see that as the angle decreases (sharper cones on the wires), both $\mathrm{K}_{\mathrm{I}}$ and $\mathrm{K}_{\mathrm{II}}$ decrease. This effect is due to the increase of surface area on the interface. In order to exploit the higher $\mathrm{K}_{\mathrm{II}}$ value, it is preferable to introduce 
some shear component along the joint. Figure 3 indicates that the lowest stress intensity, and therefore the strongest joints, is a result of having smaller apex angles. But, as the cone becomes sharper, heating along the interface will become less uniform, and complete joining may not be possible.

The NiTi is the material that will be irradiated, since it has a lower melting temperature than the stainless steel. Starting the laser a fixed distance away, and then scanning at a constant velocity towards the interface, will result in heat accumulated along the interface. At the same time, the wires are spun at a constant angular velocity, helping to ensure uniform heating. Along joint interfaces, the irradiated material will contract as it is cooled [10]. Since the conical portion of the NiTi encases the stainless steel, as this contraction occurs the NiTi will contract down and squeeze onto the stainless steel wire.

\section{Thermal Modeling}

Since heat input from the laser is the only parameter we can control during the process, 3D thermal modeling was done to help choose parameters. The heat flux due to the laser was modeled as a Gaussian distribution with a spot size of $800 \mu \mathrm{m}$. At the interface, the initial thermal resistance is large, which results in thermal accumulation. But once the interface has melted, this resistance decreases significantly. To simulate this changing conductance across the interface, a thin thermally resistive layer was placed between the NiTi and stainless steel. By equating the heat flow in the definitions of convection and conduction heat transfer, we can get the relationship

$$
h=-\frac{k}{\Delta x} \text {. }
$$

where $\mathrm{h}$ is the heat transfer coefficient per area, $\mathrm{k}$ is the thermal conductivity, and $\Delta \mathrm{x}$ is the width of the resistive layer. The non-melted NiTi-SS interface has $\mathrm{h}=79 \mathrm{~W} / \mathrm{m}^{2} \mathrm{~K}$ [29]. Values for $\mathrm{k}$ and $\Delta \mathrm{x}$ were set to give this initial ratio, and input into the resistive layer. A temperature dependent step function was associated with $\Delta x$, so that once each node of the interface reached its melting temperature, the value of $\Delta x$ would decrease, thus increasing the conductance. According to the Hagen-Ruben Relation, laser absorption can be calculated as:

$$
A=\sqrt{8 \varepsilon_{o} \omega \rho}
$$

where $\varepsilon_{0}$ is the permittivity of free space, $\omega$ is the angular frequency of incident radiation, and $\rho$ is the electrical resistivity of the material [30]. Electrical resistivity is proportional to temperature, and thus absorptivity increases as the temperature is increased. The most dramatic increase of absorptivity is when the material changes from a solid to a liquid. Since in this process melting is limited to the interface, we make the simplification of using a constant resistivity. An electrical resistivity of $5.48 \mathrm{E}-7 \Omega \mathrm{m}$ was used, which is the value for titanium at $333 \mathrm{~K}$ [31], since the titanium oxide layer that forms on the surface of the NiTi is similar to the surface of titanium. A laser with wavelength of $1064 \mathrm{~nm}$ was used, which results in an absorptivity of $26 \%$. Convective cooling is present on the outside surface of the wires, due to the argon flowing over the wire. The convective heat transfer coefficient was calculated using the Zhukauskas Correlation [32]:

$$
\begin{gathered}
\overline{N u}_{D}=\operatorname{CRe}_{D}^{m} \operatorname{Pr}^{n}\left(\frac{P r}{P r_{S}}\right)^{\frac{1}{4}} \\
\bar{h}=\overline{N u}_{D} \frac{k}{D}
\end{gathered}
$$

where $\overline{N u}_{D}$ is the average Nusselt number, $R e_{D}$ is the Reynolds number, $\mathrm{Pr}$ is the Prandtle number, $\mathrm{k}$ is thermal conductivity, D is the wire diameter, and $\mathrm{C} \& \mathrm{~m}$ are constants determined from by the Reynolds number. Using a kinematic viscosity for argon of $1.41 \mathrm{E}-4 \mathrm{~m}^{2} / \mathrm{s}$ [33], the Reynolds number was calculated as 0.92 , resulting in $\bar{h}=12.7 \mathrm{~W} / \mathrm{m}^{2} \mathrm{~K}$. The $3 \mathrm{D}$ heat equation was implemented in COMSOL. Although the temperature distribution was not directly measured, the trends predicted by this thermal model will be shown to be consistent with experimental results.

\section{PROCEDURE}

For this study, NiTi and hard tempered SS304 wires of diameter $762 \mu \mathrm{m}$ were used. The angles of the points analyzed on the stainless steel samples were $90^{\circ}$ and $120^{\circ}$, with corresponding values for the NiTi. In order to create the cones on the ends of the stainless steel wires, they were placed into an angled block, and then spun at 5000rpm against 320 grit silicon carbide abrasive paper. To create the cups in the ends of the NiTi, $1143 \mu \mathrm{m}$ diameter spot drills were used, with corresponding tip angles. After shaping, the wires were washed in acetone in an ultrasonic bath.

The NiTi wires were fastened into a rotary stage, while the stainless steel wires were placed in an un-driven ball bearing fastened onto a sliding linear stage. An axial load of 2 Newtons was applied to the linear stage. Argon was flowed into a chamber surrounding the wires at 10scfh. A SPI redENERGY G4 fiber laser operating in $\mathrm{CW}$ mode at a wavelength of $1064 \mathrm{~nm}$ was used. Power levels analyzed were $13 \mathrm{~W}, 14 \mathrm{~W}, 15 \mathrm{~W}, 16 \mathrm{~W}$, amd $17 \mathrm{~W}$. Laser spot size was $738 \mu \mathrm{m}$. The wires were rotated at an angular velocity of $3000 \% \mathrm{sec}$. The laser started $1.6 \mathrm{~mm}$ away from the interface, and was scanned towards the interface at a linear velocity of $0.22 \mathrm{~mm} / \mathrm{s}$. It was stopped $0.1 \mathrm{~mm}$ short of the interface. This corresponds to a total rotation of $20,450^{\circ}$ with the laser irradiating for $6.82 \mathrm{~s}$.

Tensile testing was carried out according to ASTM E811 standards [34]. An Hitachi-S4700 SEM with energy dispersive X-ray spectroscopy (EDX) attachment was used for the compositional analysis.

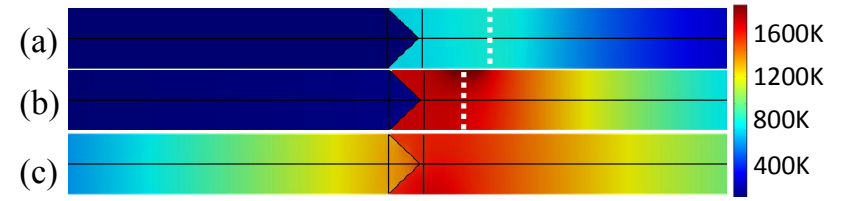

Figure 4 Longitudinal sectioned time snapshot of thermal accumulation in of $90^{\circ}$ cones. Corresponding times are: (a) $1 \mathrm{~s}$, (b) $4 \mathrm{~s}$, (c) $6.8 \mathrm{~s}$ (laser has shut off). Laser location indicated by white dotted line. Power: $15 \mathrm{~W}$, Angular velocity: $3000 \% \mathrm{~s}$ 


\section{RESULTS \& DISCUSSION Thermal Model}

In Figure 4, a longitudinal section view of the wires is plotted displaying temperature at three different times during the laser scan. As the NiTi wire begins to heat up, thermal accumulation at the interface occurs due to the interfacial resistance. This indicates that most of the melting should be limited to the interface, which is desirable. If excessive melting occurred along the whole path of the laser scan, the wire would lose its structural integrity and deform. Due to the rotation of the wires, the hot temperature is able to reach to the extents of the NiTi cone, both points 1 and 2. Had the wires not been rotated during irradiation, insufficient heat would have been able to conduct to the apex. Once the interface has melted, the NiTi wets onto the stainless steel side, and the thermal resistivity across the interface decreases. The third time snapshot is after wetting has occurred, and the stainless steel wire is seen to heat up.

An even temperature distribution along the interface is desired, since this will allow for uniform melting. Figure 5 displays the temperature distribution along the line segment from points 1 to 2 at the moment the laser has completed its scan. Of the three different angular velocities, $3000 \mathrm{deg} / \mathrm{s}$ has the flattest temperature distribution. It is also apparent that increasing the angular velocity increases the average temperature of the interface. As the wire is being spun faster, the input heat flux from the laser beam behaves more like a uniform ring of heat around the circumference of the wire, as opposed to a single point source. The overall power from the laser is the same, but the uniform heating may decrease the temperature gradient in the vertical direction, resulting in less heat being conducted away. Figure 6 displays the time history for points 1 and 2, and for points on the top and bottom of the

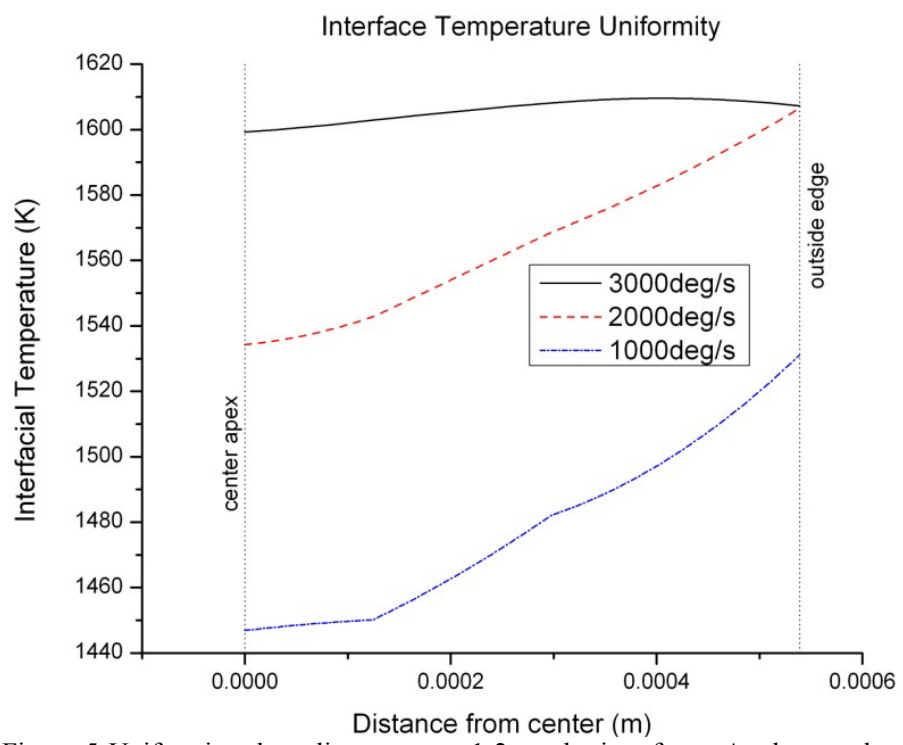

Figure 5 Uniformity along line segment $1-2$ on the interface. As the angular velocity is increased, the thermal distribution becomes more even.

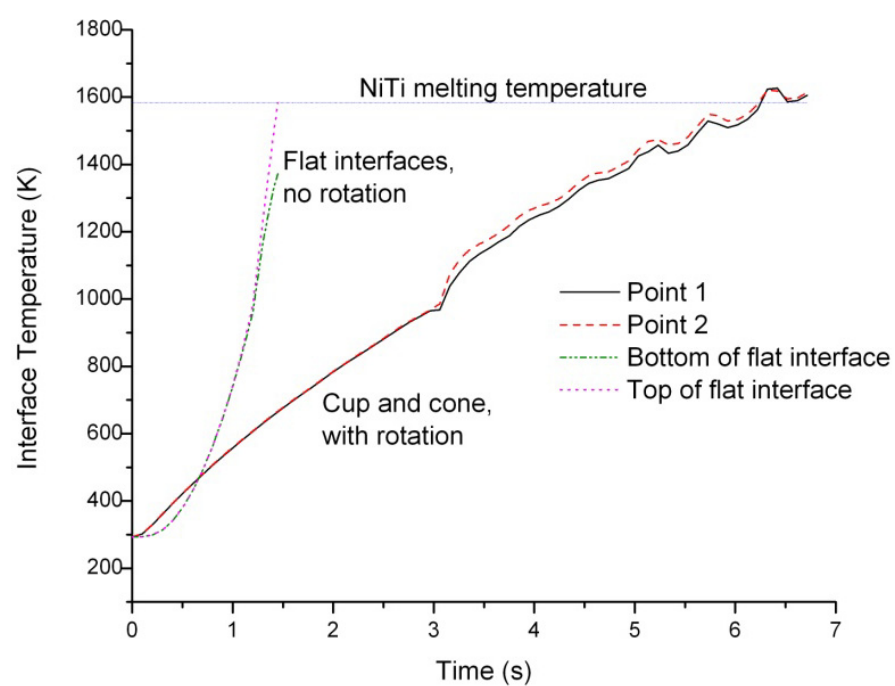

Figure 6 Time history of points 1 and 2 along the interface from Figure 2, compared to points at the top and bottom of the interface of wires with flat interfaces. Temperature difference between the 2 points throughout the laser scan is minimal. Laser power is $15 \mathrm{~W}$ for the rotated wires, and $35 \mathrm{~W}$ for the flat interfaces.

interface of wires with flat interfaces that were not rotated during irradiation. We are looking for the maximum temperature difference along each wire's interface. Due to symmetry, the largest temperature difference on the rotated wires is between the outside point 2 and the apex point 1 . For the non-rotated wires, the largest difference is between points at the top and bottom of the interface. At 1.5 seconds, the top of the flat wires is nearly $1700 \mathrm{~K}$, while the bottom is only $1400 \mathrm{~K}$. By examining longitudinally sectioned samples that were not rotated, we see that often the top is overmelted, while no melting occurs at the bottom. This is consistent with the predictions of the thermal model. If laser power is increased to allow for the bottom point to reach melting temperature, the top point will reach excessive temperatures. The temperatures at the two points on the interface that was rotated reach the melting temperature at nearly the same time, which will results in good uniformity of the joint.

\section{Joint Morphology}

Outside images of four of the joints are presented in the Figure 7. Most apparent is the effect of thermal accumulation, in that the majority of the melting occurs in the NiTi near the interface. More melting is evident in both of the wires that are at $15 \mathrm{~W}$. The interface for this power level tends to bulge out more than it does at $13 \mathrm{~W}$. But for their respective power levels, the $90^{\circ}$ wires tend to have a larger belled region than the $120^{\circ}$ wires do. The cone is deeper in the $90^{\circ}$ wires, so the walls near the end of the NiTi are much thinner for a longer distance. It takes very little heat to melt these thin walls, which may result in the apparently larger melted region of the $90^{\circ}$ wires.

Longitudinal section images of samples from $15 \mathrm{~W}$ and $17 \mathrm{~W}$ are presented in Figure 8 and 9. In both of the images, the cup and cone geometry is still intact. Along the angles of the 
interface, a possibly mixed region is visible. These regions will be analyzed via EDX. In the $15 \mathrm{~W}$ wire, joining is apparent throughout the center of the wire. But, within the mixed region, a large circular defect is present. Also, joining is not apparent at the apex of the cone. This region will act as an initial crack during tensile testing, resulting in a lower fracture strength. The apex of the $17 \mathrm{~W}$ wire also does not appear to have complete joining, yet excessive deformation occurred on the outside. Therefore, continuing to increase the power will not result full joining of the interface. Alternatively, varying other parameters, such as angular velocity, could help to achieve more melting at the apex.
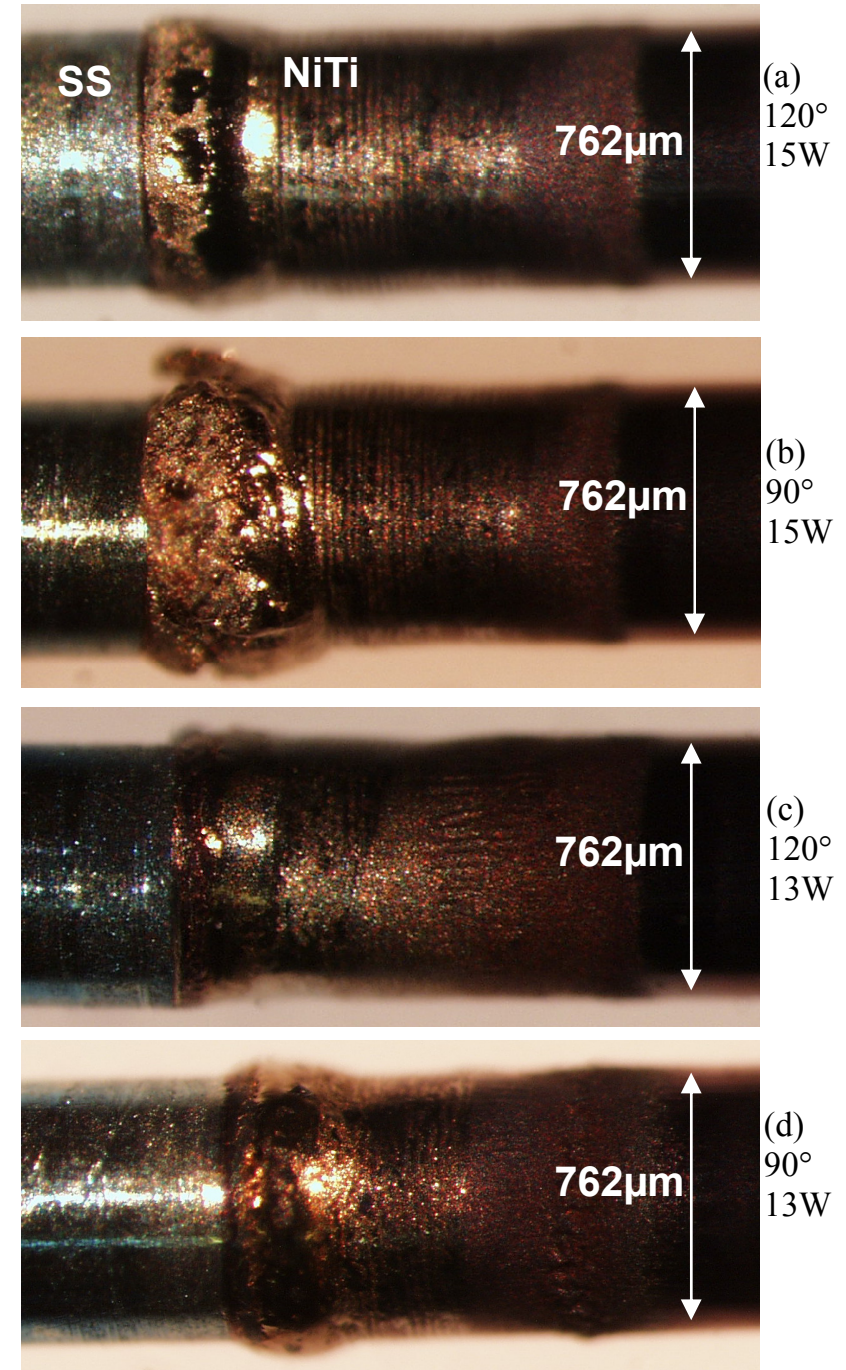

Figure 7 Images of four different combinations of power and cone angle. The outer surface near the joint of the $90^{\circ}$ wires experienced more deformation. Rotational velocity is held constant at $3000^{\circ} / \mathrm{s}$.

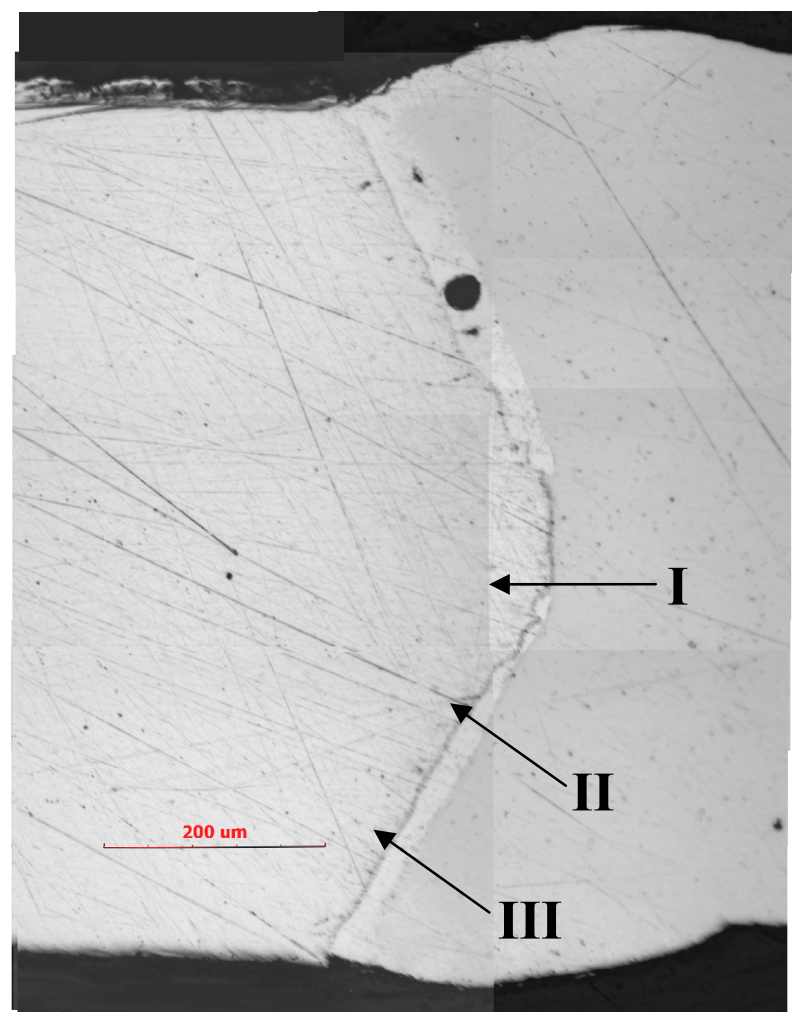

Figure 8 Longitudinal section image of a $120^{\circ}$ cone processed at a power of $15 \mathrm{~W}$. The arrows indicate the paths of EDX line scans.

\section{Composition}

The width of the mixed region, where brittle intermetallics will form, is critical to the fracture strength of each joint. EDX line profiles were acquired along arrows I, II, and III indicated in Figure 8. A line profile for III is displayed in Figure 10. The region from $37 \mu \mathrm{m}$ to $65 \mu \mathrm{m}$ is where mixing of the NiTi and stainless steel occurred. All of the scans along II and III for both power levels had very similar shape, with just the width of this mixing layer being the only difference. An abrupt transition happens between the mixed region and the base materials. To determine which phases are forming, we compare the compositions to the ternary phase diagram of Figure 1. Since it does not appear on the phase diagram, the amount of chromium is neglected, which will slightly increase the concentrations from those displayed on the line scan. Two peaks stand out, one where titanium reaches nearly $50 \%$ and the other where nickel reaches nearly $50 \%$. For both of these, the iron level is between $10-20 \%$. Comparison with the phase diagram indicates that these are regions of $(\mathrm{Fe}, \mathrm{Ni}) \mathrm{Ti}$. The widest mixing zone occurred on III for the wire processed at $15 \mathrm{~W}$ shown in Figure 11, with a width of $33 \mu \mathrm{m}$. Instead of having a flat trend along the length, this joint has more of a slow transition from the NiTi to the stainless steel. This is 


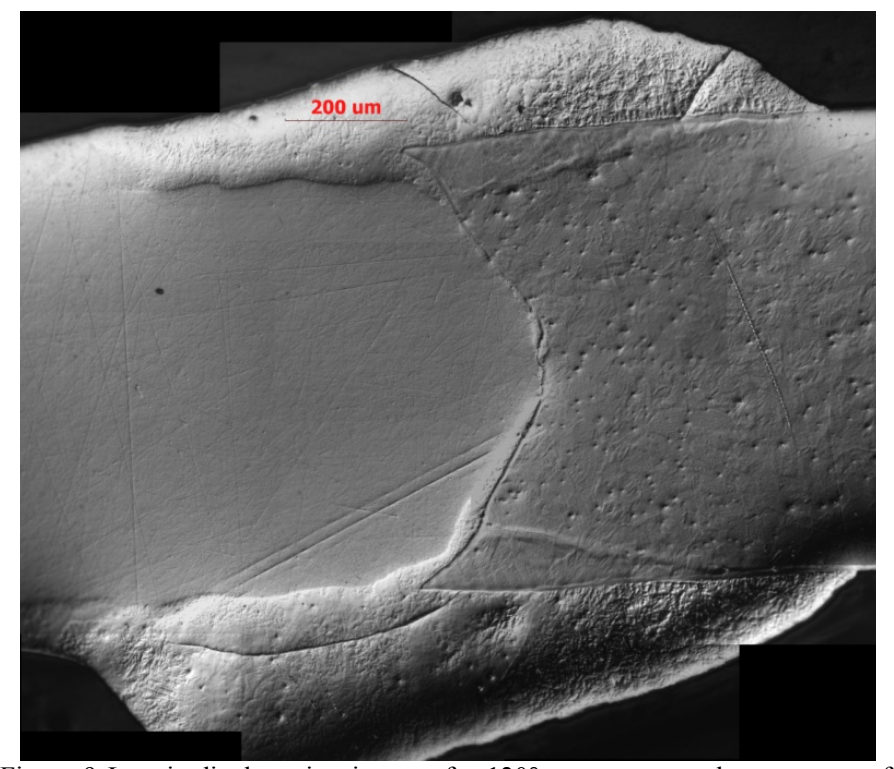

Figure 9 Longitudinal section image of a $120^{\circ}$ cone processed at a power of 17W. Excessive melting and deformation is present on the outer surface.

evidence that diffusion of the materials has taken place. The thinnest mixing zone occurred on II for the wire processed at $13 \mathrm{~W}$, with a width of only $18 \mu \mathrm{m}$. Analysis on I for both samples showed no mixing zone, indicating that joining did not occur at the centers. Table 1 displays the width measurements for each scan. As expected, the mixing for the $13 \mathrm{~W}$ sample is consistently lower than that of the $15 \mathrm{~W}$.

\section{Joint Strength}

The average load at fracture for a sample of wires is presented in Figure 13. All of the wires fractured along the interface. For both the $90^{\circ}$ and $120^{\circ}$ wires, an upward trend with power is evident. Also, as the power increases the variance in tensile strength decreases. This higher consistency is attributed to the excess melting that occurs under the higher powers. When the wires are being rotated under the laser, there is some slight unavoidable alignment error. At $17 \mathrm{~W}$, the large melt pool is able to fill in the gaps that are not perfectly aligned. This does not occur at the lower power levels, and thus they will be more sensitive to the alignment. For $13 \mathrm{~W}$ through $16 \mathrm{~W}$, the $90^{\circ}$ angle wires have higher average fracture strength than the $120^{\circ}$ angle wires. This is consistent with the idea that increasing the interface surface area will allow for higher fracture loads. But, at $17 \mathrm{~W}$, the $120^{\circ}$ wires have a higher average load. It is possible that at this higher power, the increased surface area allowed for more formation of brittle intermetallic phases.

\begin{tabular}{|l|l|l|l|}
\hline & I & II & III \\
\hline $13 W$ & 0 & 18 & 28 \\
\hline $15 W$ & 0 & 27 & 33 \\
\hline
\end{tabular}

Table 1 Interface thicknesses (microns) across different regions of the joint. Scans I, II, III are indicated in Figure 8. Zero thickness at I is reported because no melt and subsequent mixing occurred in the centermost region of either sample.
Due to the axial load, the cross sectional area of the joint increases during processing. The loads at fracture have been normalized by the cross sectional area of the fracture, and are plotted in Figure 14. Here we see that the fracture strength will actually decrease with overheating. This is evidence that too much mixing occurs at the higher power levels, and therefore large amounts of brittle intermetallics are forming. At $14 \mathrm{~W}$, the $90^{\circ}$ wires have an average strength of about $310 \mathrm{MPa}$, which is the highest level reached for any of the parameters. The highest strength of $270 \mathrm{MPa}$ for the $120^{\circ}$ wires occurs at $15 \mathrm{~W}$. The ideal power level is where the minimum amount of melting occurs. Due to their sharper angle, the $90^{\circ}$ wires overlap more than the $120^{\circ}$ wires, resulting in better contact. The amount of melting at $14 \mathrm{~W}$ may be ideal to join the $90^{\circ}$ wires together, but the $120^{\circ}$ wires need slightly more melting in order to overcome some small misalignment effects. For all 13 Watts

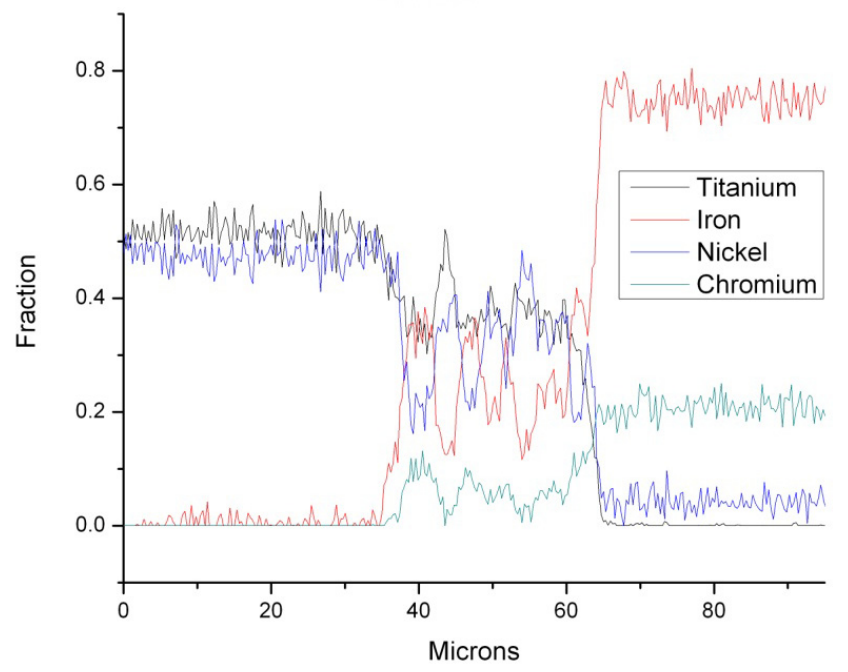

Figure 10 EDX line scan across line III, indicating the mixing occurring in the joint. Sample irradiated at $13 \mathrm{~W}$.

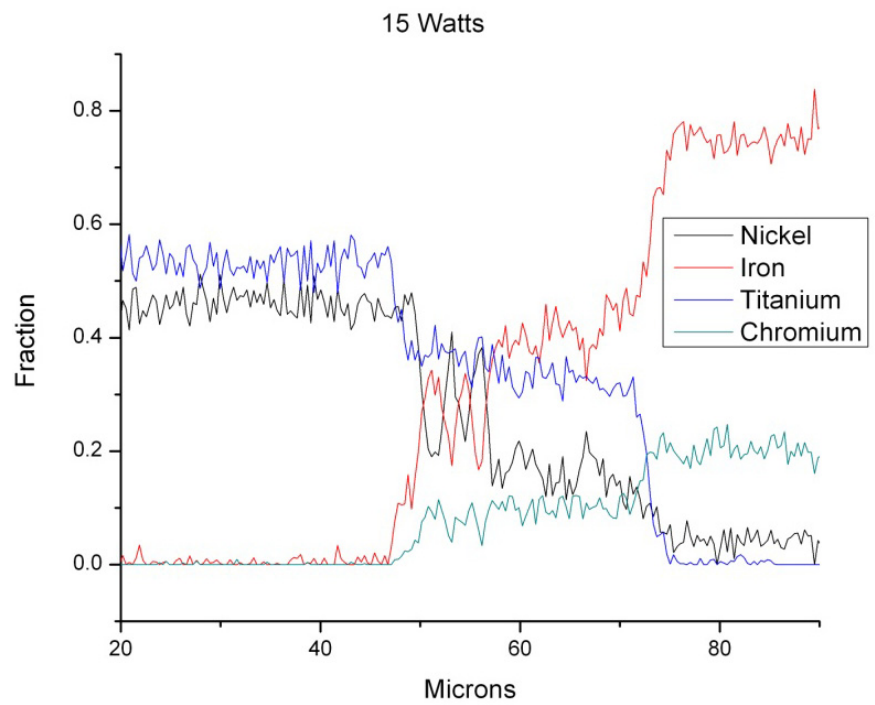

Figure 11 EDX line scan across region III indicated in Figure 8. Gradual decrease of concentration across the width of the interface is indicative of diffusion. Sample irradiated at $15 \mathrm{~W}$. 


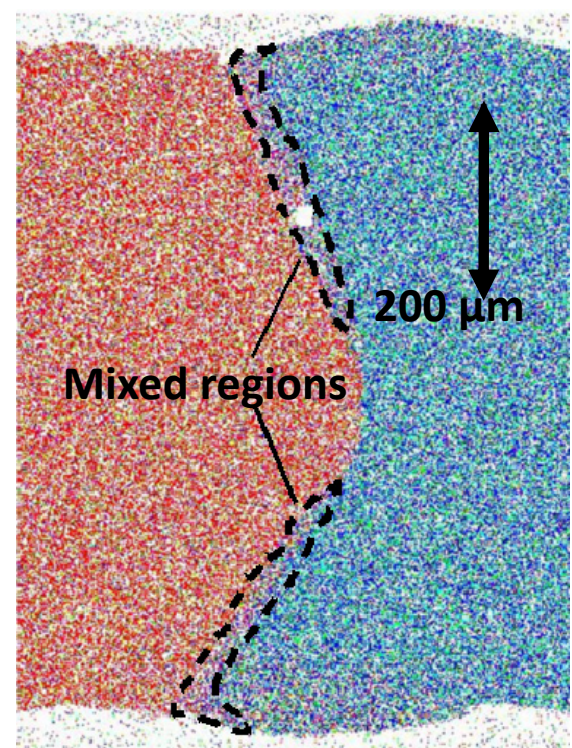

Figure 12 EDX compositional map, corresponding to the longitudinal sectioned image of Figure 7, showing iron (red), nickel (green), and titanium (blue). Laser power is $15 \mathrm{~W}$. A mixing region is observed along the interface, the width of which decreases towards the center of the wire. This indicates that the lighter colored regions along the interface of the longitudinal sectioned images are indeed the mixed regions.

power levels aside from $13 \mathrm{~W}$, the $90^{\circ}$ wires have the higher of the two strengths. This chart is normalized to cross sectional area, but the overall interface area of the $90^{\circ}$ wires is still larger, indicating that increasing surface area due to different joint geometry can increase the fracture strength of these wire joints. However, it is noted that standard stainless steel 304 yields at $205 \mathrm{MPa}$. Clearly, the samples ran at $13-17 \mathrm{~W}$ are above this yield strength.

For comparison, fracture strength of wires of the same diameter with a simple flat interface was also tested. These wires were held stationary, and irradiated at a power of $35 \mathrm{~W}$ as

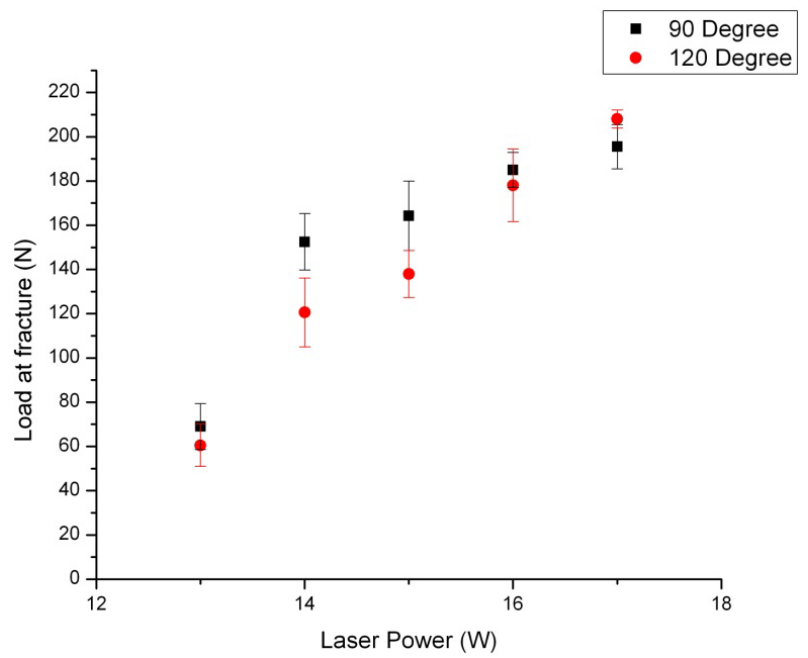

Figure 13 Increase of load at fracture with increasing laser power input. Standard error for each level is indicated. Note that the $90^{\circ}$ wires are stronger than the $120^{\circ}$ wires at every power except for $17 \mathrm{~W}$. the laser was scanned towards the interface. As previously shown in the thermal model, rotation of the wires allows for more heating across the depth of the wires. Since the flat wires were not spun, more power input was required in order to achieve melting across the entire interface. The results are displayed in Figure 15, with $180^{\circ}$ corresponding to the flat interfaces. We see that the wires that had the cup and cone geometry, and were rotated during irradiation, are indeed stronger than the non-rotated flat tests. The error for the rotated wires is also much smaller as well. During processing of the flat interfaces, the high laser power required to melt the bottom of the interface results in excessive melting of the top surface.

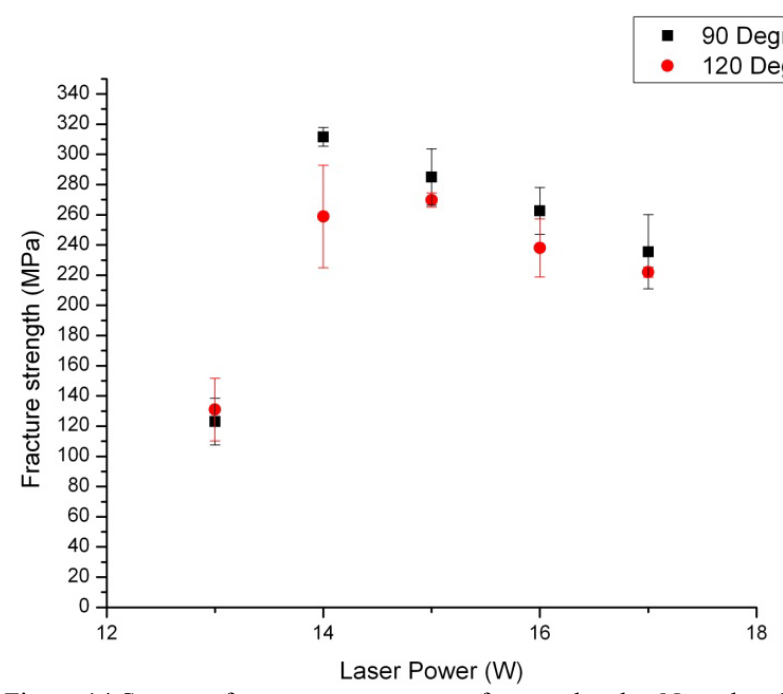

Figure 14 Stress at fracture over a range of power levels. Note that the highest strengths for the $90^{\circ}$ samples occurred at a different power level than for the $120^{\circ}$ samples. Standard error is indicated.

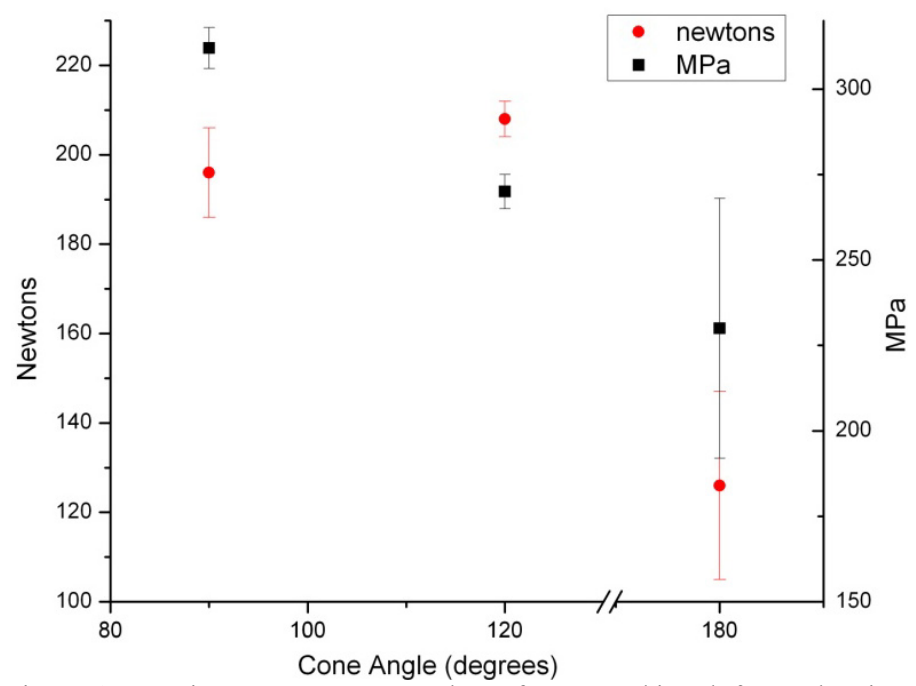

Figure 15 Maximum average strength at fracture achieved for each wire geometry. Standard error is indicated. The $180^{\circ}$ samples are the non-rotated, flat interfaces. Both of the conical wires have much higher fracture strengths. 


\section{CONCLUSION}

The effect of using a cup and cone interfacial geometry for joining of NiTi-SS wires has been explored. Rotation of the wires during laser irradiation was used. This rotation produced much more uniform heating of the interface. Joints that had a $90^{\circ}$ apex angle of the cone were found to have the highest fracture strength. The optimal laser power level for the $90^{\circ}$ wires was $14 \mathrm{~W}$, while $15 \mathrm{~W}$ for the $120^{\circ}$ wires produced the strongest joints. EDX analysis indicated $(\mathrm{Fe}, \mathrm{Ni}) \mathrm{Ti}$ formation in a thin region along the interface with a decreasing width towards the center of the wire. Even for the samples where excessive melting of the outside surface occurred, the apex of the cone in the center of the wires did not sufficiently melt. Thus, the effects that parameters such as rotational velocity have on the thermal profile of the interface must be explored. Even though cones with sharp apex angles are desirable with respect to the stress intensity formulation, limitations do exist for how small of apex angles can be used. Temperature uniformity will decrease as the apex angle is decreased. Also, the wall thickness of the NiTi cupped wires will decrease with sharper angles. These thin walls will be more sensitive to overheating, and also may fracture from shear loads that are applied.

\section{ACKNOWLEDGEMENTS}

The authors acknowledge financial support from Columbia University and NSF under GOALI Award CMMI 1130564. Use of characterization equipment in the Shared Materials Characterization Laboratory, Columbia University, is also acknowledged.

\section{REFERENCES}

[1] Duerig T., Pelton a, and Stöckel D., 1999, "An overview of nitinol medical applications," Materials Science and Engineering: A, 273-275, pp. 149-160.

[2] Avery R. E., 1991, "Pay attention to dissimilar-metal welds Guidelines for welding dissimilar metals," Chemical Engineering Progress, (May).

[3] Mubashar A., Ashcroft I. a., Critchlow G. W., and Crocombe A. D., 2011, "Strength prediction of adhesive joints after cyclic moisture conditioning using a cohesive zone model," Engineering Fracture Mechanics, 78(16), pp. 2746-2760.

[4] Hand H. M., Arah C. O., McNamara D. K., and Mecklenburg M. F., 1991, "Effects of environmental exposure on adhesively bonded joints," International Journal of Adhesion and Adhesives, 11(1), pp. 15-23.
Schubert E., Zerner D. I., and Sepold P. G., "Laser Beam Joining of Material Combinations for Automotive Applications," SPIE, 3097, pp. 212-221.

[6] Yamamoto N., Liao J., Watanabe S., and Nakata K., 2009, "Effect of Intermetallic Compound Layer on Tensile Strength of Dissimilar Friction-Stir Weld of a High Strength Mg Alloy and Al Alloy," Materials Transactions, 50(12), pp. 2833-2838.

[7] Yan Y., Zhang D., Qiu C., and Zhang W., 2010, "Dissimilar friction stir welding between 5052 aluminum alloy and AZ31 magnesium alloy," Transactions of Nonferrous Metals Society of China, 20, pp. s619-s623.

[8] Mathieu A., Shabadi R., Deschamps A., Suery M., Matteï S., Grevey D., and Cicala E., 2007, "Dissimilar material joining using laser (aluminum to steel using zinc-based filler wire)," Optics \& Laser Technology, 39(3), pp. 652-661.

Satoh G., Yao Y. L., and Qiu C., 2011, "Strength and Microstructure of Laser Fusion Welded Ti-SS Dissimilar Material Pair,” NAMRI/SME vol 39.

[10] Schwartz M. M., 1979, Metals Joining Manual, McGraw-Hill, New York.

[11] Otsuka K., and Ren X., 2005, "Physical metallurgy of Ti-Ni-based shape memory alloys," Progress in Materials Science, 50(5), pp. 511-678.

[12] De Keyzer J., "Thermodynamic modeling of the Fe-NiTi system: a multiple sublattice approach," University of Leuven.

[13] Westbrook J. H., 1967, "Historical Sketch," Intermetallic Compounds, J.H. Westbrook, ed., Robert E. Krieger Publishing Co., Inc., New York, pp. 3-14.

[14] Vannod J., 2011, "Laser Welding of Nickel-Titanium and Stainless Steel Wires: Processing, Metallurgy and Properties," Ecole Polytechnique Federale De Lausanne.

[16] Martins T. B., and Rechenberg H. R., 2006, "Antiferromagnetic $\mathrm{TiFe} 2$ in applied fields: experiment and simulation," pp. 1273-1277. 
[17] Ghosh M., and Chatterjee S., 2002, "Characterization of transition joints of commercially pure titanium to 304 stainless steel," Materials Characterization, 48(5), pp. 393-399.

[18] Eijk C. Van Der, Fostervoll H., Sallom Z. K., and Akselsen O. M., 2003, "Plasma Welding of NiTi to NiTi, Stainless Steel and Hastelloy C276," (October), pp. 13-15.

[19] Borrisutthekul R., Yachi T., Miyashita Y., and Mutoh Y., 2007, "Suppression of intermetallic reaction layer formation by controlling heat flow in dissimilar joining of steel and aluminum alloy," Materials Science and Engineering: A, 467(1-2), pp. 108-113.

[20] Cacciamani G., De Keyzer J., Ferro R., Klotz U. E., Lacaze J., and Wollants P., 2006, "Critical evaluation of the $\mathrm{Fe}-\mathrm{Ni}$, Fe-Ti and Fe-Ni-Ti alloy systems," Intermetallics, 14(10-11), pp. 1312-1325.

[21] Khalil-allafi J., Dlouhy A., and Eggeler G., 2002, "Ni 4 Ti 3 -precipitation during aging of NiTi shape memory alloys and its influence on martensitic phase transformations," 50, pp. 4255-4274.

[22] Ortega A. M., Tyber J., Frick C. P., Gall K., and Maier H. J., 2005, "Cast NiTi Shape-Memory Alloys," Advanced Engineering Materials, 7(6), pp. 492-507.

[23] Liu Y., and Mccormick P. G., 1994, "Thermodynamic analysis of the martensitic transformation in NiTi Effect of heat treatment on transformation behaviour," Acta metall. mater, 42(7), pp. 2401-2406.

[24] Vaidya W. V., Horstmann M., Ventzke V., Petrovski B., Koçak M., Kocik R., and Tempus G., 2010, "Improving interfacial properties of a laser beam welded dissimilar joint of aluminium AA6056 and titanium Ti6A14V for aeronautical applications," Journal of Materials Science, 45(22), pp. 6242-6254.

[25] Vaidya W. V., Horstmann M., Ventzke V., Petrovski B., Koçak M., Kocik R., and Tempus G., 2009, "Structure-property investigations on a laser beam welded dissimilar joint of aluminium AA6056 and titanium Ti6Al4V for aeronautical applications Part I: Local gradients in microstructure, hardness and strength," Materialwissenschaft und Werkstofftechnik, 40(8), pp. 623-633.

[26] Ogata Y., Takatugu M., Kunimasa T., Uenishi K., and Kobayashi K. F., 2004, "Tensile Strength and Pseudoelasticity of YAG Laser Spot Melted Ti-Ni Shape
Memory Alloy Wires," Materials Transactions, 45(4), pp. 1070-1076.

[27] Hertzberg R. W., 1996, Deformation and Fracture Mechanics of Engineering Materials, John wiley \& Sons, Inc., New York.

[28] Awaji H., and Kato T., 1999, “Awaji - Criterion for combined mode I-II brittle fracture.pdf," Materials Transactions, 40(9), pp. 972-979.

[29] Ifflander R., 2001, Solid-State Lasers for Materials Processing, Springer-Verlag, New York.

[30] Xie J., Kar A., Rothenflue J. A., and Latham W. P., 1997, "Temperature-dependent absorptivity and cutting capability of CO 2 , Nd: YAG and chemical oxygen iodine lasers," Journal of Laser Applications, 9, pp. 7785.

[31] Bel'skaya E. A., 2005, “An Experimental Investigation of the Electrical Resistivity of Titanium in the Temperature Range from 77 to $1600 \mathrm{~K}$," High Temperature, 43(4), pp. 546-553.

[32] Incropera F. P., and DeWitt D. P., 2002, Fundamentals of Heat and Mass Transfer, John wiley \& Sons, Inc., Hoboken, NJ.

[33] Younglove B. A., and Hanley J. M., 1986, “The Viscosity and Thermal Conductivity Coefficients of Gaseous and Liquid Argon," Journal of Physical and Chemical Reference Data, 15(4), pp. 1323-1337.

[34] ASTM Standard E8/E8M-11, "Standard test methods for tension testing of metallic materials," ASTM International, West Conshohocken, PA, 2001, DOI: 10.1520/E0008 E0008M-11. 